\title{
Etiological Evaluation of Congenital Hypothyroidism in Cases Referred from the National Screening Program
}

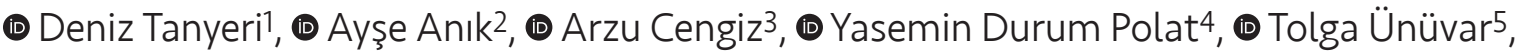 \\ (1) Ahmet Anık5
}

${ }^{1}$ Aydın Adnan Menderes University Faculty of Medicine, Department of Pediatrics, Aydın, Turkey

${ }^{2}$ Aydın Adnan Menderes University Faculty of Medicine, Department of Neonatology, Aydın, Turkey

${ }^{3}$ Aydın Adnan Menderes University Faculty of Medicine, Department of Nuclear Medicine, Aydın, Turkey

${ }^{4}$ Aydın Adnan Menderes University Faculty of Medicine, Department of Radiology, Aydın, Turkey

${ }^{5}$ Aydın Adnan Menderes University Faculty of Medicine, Department of Pediatric Endocrinology, Aydın, Turkey

\begin{abstract}
Aim: To evaluate cases referred from the congenital hypothyroidism $(\mathrm{CH})$ new-born screening program.

Materials and Methods: One hundred and thirty-five cases which were referred between January 2017 and July 2019 were included in the study. Results: Fourty eight of 135 cases (35.6\%) were diagnosed as $\mathrm{CH}$. The mean onset of treatment was $17.31 \pm 9.92$ days. Clinical findings suggesting hypothyroidism were detected in 27 patients (56.2\%) and goiter was detected in 2 patients (4.1\%). According to imaging findings, 16 (35.5\%) patients were diagnosed as dysgenesis, $[1(2.2 \%)$ as agenesia, $3(6.7 \%)$ as ectopia, and $12(26.6 \%)$ as hypoplasia], 11 were diagnosed as dyshormonogenesis ( $24.5 \%$ ), and 18 were diagnosed as eutopic thyroid (40\%). The mean levothyroxine dose was $12.7 \pm 2.5 \mathrm{mcg} / \mathrm{kg} / \mathrm{day}$ and the mean onset of treatment in $30.4 \%$ of diagnosed patients was within the first 14 days and $93.3 \%$ were within the first 30 days.

Conclusion: Dysgenesis and dyshormonogenesis are the most common detectable causes of $\mathrm{CH}$. The normal localization of the thyroid gland in about half of the patients suggests that transient causes of $\mathrm{CH}$ may be more common than expected. Considering that only $1 / 3$ of the patients were treated in the first 2 weeks, it was thought that the referral of patients is still an important problem and it should be done more promptly.
\end{abstract}

Keywords: Congenital hypothyroidism, neonatal screening program, etiology

\section{Introduction}

Congenital hypothyroidism $(\mathrm{CH})$ is defined as the deficiency of thyroid hormones in newborn babies, with an incidence of 1 in 1,400 to $2,800(1,2)$. Due to the essential role of thyroid hormones in brain development, its deficiency can have devastating effects on neurocognitive development if not detected and treated early and effectively (1). The lack of obvious clinical manifestations of hypothyroidism in newborns, reinforces the pivotal role of newborn screening in facilitating prompt diagnosis and treatment.

The most frequent method used for screening for $\mathrm{CH}$ in the world, as well as in our country, is the measurement

\section{Address for Correspondence}

Ahmet Anık MD, Aydın Adnan Menderes University Faculty of Medicine, Department of Pediatric Endocrinology, Aydın, Turkey Phone: +90 2562145400 E-mail: ahmet.anik@yahoo.com ORCID: orcid.org/0000-0002-7729-7872

Received: 17.03 .2020 Accepted: 02.04 .2020

${ }^{(0)}$ Copyright 2021 by Ege University Faculty of Medicine, Department of Pediatrics and Ege Children's Foundation The Journal of Pediatric Research, published by Calenos Publishing House. 
of thyroid stimulating hormone (TSH) from the heel-stick blood sample between the $2^{\text {nd }}$ and $5^{\text {th }}$ days of life (3). Screening for $\mathrm{CH}$ in Turkey was started in 2006 and the incidence of $\mathrm{CH}$ in Turkey was reported as 1 in 888 in 2008, 1 in 592 in 2009 and 1 in 469 in 2010 (4). Though the prevalence of $\mathrm{CH}$ in our country is not exactly known, various studies reported that transient $\mathrm{CH}$ varies between 25 and 65\% (5-9). Considering the increasing frequency in recent years, it is becoming more important to determine the etiological factors of $\mathrm{CH}$.

The aim of this study was to evaluate the rate of diagnosis of $\mathrm{CH}$ in referred patients from the national screening program; as well as the clinical and laboratory features and etiological distributions of the patients.

\section{Materials and Methods}

In this study, cases with high capillary TSH who were referred from the national screening program to our hospital were retrospectively evaluated. This study was carried out in Aydın province located in the Aegean region. The study was approved by the Aydın Adnan Menderes University Faculty of Medicine, Non-Interventional Clinical Research Ethics Committee (date: 22.08.2019, approval number: 2019/125).

$\mathrm{CH}$ was diagnosed according to ESPE guidelines (10):

- Venous TSH level $>20 \mathrm{mIU} / \mathrm{L}$ and fT4 level normal or low $(<0.7 \mathrm{ng} / \mathrm{dL})$

- Patients whose venous fT4 level is within normal limits (0.7-1.48 $\mathrm{ng} / \mathrm{dL}$ ) and TSH level is between $6-20 \mathrm{mIU} / \mathrm{L}$ and those with normal fT4 levels and increased TSH levels underwent repeated weekly measurements until postnatal $21^{\text {st }}$ day of life.

The demographic information of the patients, postnatal age, birth week, birth weight, family history of thyroid disease, consanguinity, physical examination and perinatal event details including complaint, anthropometric data, heel-stick blood sample time and results, and laboratory and imaging results were obtained from the hospital recording system. In addition, serum $\mathrm{fT} 4$, TSH, thyroglobulin (TG), ultrasonographic features (localization, volume, parenchymal echogenicity of the thyroid gland), and thyroid scintigraphy (localization and activity of the thyroid gland) and serum thyrotropin receptor antibodies (TRB-Ab) level in those patients with maternal thyroid disease were also recorded from the same data.

Laboratory and imaging tests of all patients were performed on the same day. TSH and fT4 were measured by chemiluminometric assay with Abbott Architect i2000. TC levels were measured by two different immunoassay methods (ROCHE cobas 601 and ROCHE cobas E411). The TRB-Ab level was measured by the radioimmunoassay method (STRATEC-GAMA READER and TRAC ETIMAX).

Thyroid ultrasonography was performed by the same pediatric radiologist using the L3-12A broadband highresolution linear probe with a frequency range of 3-12 $\mathrm{MHz}$ with the Samsung Medison RS80A Prestige (Samsung Medison Co. Ltd., Seoul, Korea). The longest longitudinal (D1), anterior-posterior (D2), transverse (D3) diameter and isthmus thickness were recorded separately for both lobes of the thyroid gland. The volume for each lobe and the entire gland in millilitres was automatically calculated according to the formula [width $x$ length $x$ depth $x \pi / 6(0.523)$ ] in the Child Metrics program (11). Those volumes of thyroid gland between 0.526-1.849 $\mathrm{mL}$ for the entire gland, 0.228-0.931 $\mathrm{mL}$ for the right lobe, and $0.294-0.959 \mathrm{~mL}$ for the left lobe were considered as normal (12). Results below these values were considered as hypoplasia and above as hyperplasia.

Twenty minutes after 500-750 $\mathrm{\mu Ci}$ Technetium-99m pertechnetate intravenous injection, thyroid scintigraphy was performed via a Siemens syngo via device and gamma camera and images were recorded for a total of 5 minutes. Anatomical localization of the gland and activity (decreased, increased, or normal) of these images were evaluated by the same nuclear medicine specialist.

Patients with agenesis, ectopia or hypoplasia according to imaging results were classified as dysgenesis; while patients with a history of consanguinity and increased activity in the thyroid gland, or with increased activity and hyperplasia were classified as dyshormonogenesis. The remaining patients were classified as eutopic thyroid, which could be transient $\mathrm{CH}$. The given starting LT4 dose was recorded in $\mathrm{mcg} / \mathrm{kg} / \mathrm{day}$.

\section{Statistical Analysis}

Kolmogorov-Smirnov test was used to test whether the quantitative variables are suitable for normal distribution. The groups were compared with two independent samples t-test for normally distributed variables and Mann-Whitney $U$ test for abnormally distributed variables. Chi-square analysis was used to test whether there is independence between qualitative variables. Descriptive statistics of variables with normal distribution were expressed as "mean \pm standard deviation" and descriptive statistics of abnormally distributed quantitative variables as "median $\left(25^{\text {th }}-75^{\text {th }}\right.$ percentile)". Descriptive statistics of qualitative variables were expressed in frequency (\%). $\mathrm{P}<0.05$ values were considered statistically significant. 


\section{Results}

Of the 135 cases included in the study, 48 (35.6\%) were diagnosed with $\mathrm{CH}$, and 87 (64.4\%) cases were healthy. The average age at admission was $19.05 \pm 9.87$ days for the whole study population, and it was $17.3 \pm 9.9$ days in those babies with $\mathrm{CH}$. The average gestational week of the 48 patients with $\mathrm{CH}$ [19 (39.6\%) female, 29 (60.4\%) male] was 38.7 \pm 1.7 weeks, among which, 40 of the cases were term (83.3\%) and 8 were preterm babies (16.7\%). The mean birth weight was $3,130.1 \pm 455.3 \mathrm{~g}$. There was no significant difference between the group diagnosed with $\mathrm{CH}$ and the healthy group in terms of age of presentation, birth week, birth weight, term/preterm rate, and gender distribution ( $p>0.05$ ) (Table I). Body weight, height and head circumference at the time of presentation were similar in both groups.

The average first and second screening times of those patients diagnosed with $\mathrm{CH}$ was 6 (4-8) and 10 days (8-14), respectively. The average first screening of TSH level was $10.22 \mu \mathrm{lU} / \mathrm{mL}$ (6.47-17.69) and the second was $20.06 \mu \mathrm{IU} / \mathrm{mL}$ (9.5-25.63) (Figure 1). The average time to start treatment was $17 \pm 9$ days in those patients with $\mathrm{CH}$.

There was a family history of thyroid disease in 17 (34.4\%) of those patients with $\mathrm{CH}$, and history of consanguinity between parents in 11 (22.9\%) cases. There were 4 patients with $\mathrm{CH}$ whose mother had hypothyroidism and TRB-Ab was negative in all of these babies. No significant difference was found between the group with $\mathrm{CH}$ and the healthy group in terms of family history of thyroid disease and consanguinity. lodine exposure was present in 16 (11.9\%) cases in the whole group and in 5 (10.4\%) of those patients with $\mathrm{CH}$. This exposure was due to iodine-containing antiseptics that were used for umbilical care in all cases.

The average TSH level at the time of diagnosis was $62.94 \pm 49.33 \mu \mathrm{lU} / \mathrm{mL}$ in the $\mathrm{CH}$ group, and $3.1 \mu \mathrm{lU} / \mathrm{mL}$ (0.77$4.81)$ in the control group. The average fT4 level was 0.63 $\mathrm{ng} / \mathrm{dL}(0.22-1.22)$ in the $\mathrm{CH}$ group; and $1.09 \pm 0.14 \mathrm{ng} / \mathrm{dL}$ in the control group. Thirty patients (62.5\%) with $\mathrm{CH}$ had low fT4 levels $(<0.7 \mathrm{ng} / \mathrm{dL})$ at the time of diagnosis. Serum TSH and fT4 levels at the time of admission were statistically significant between the two groups $(p<0.001)$ (Table II).

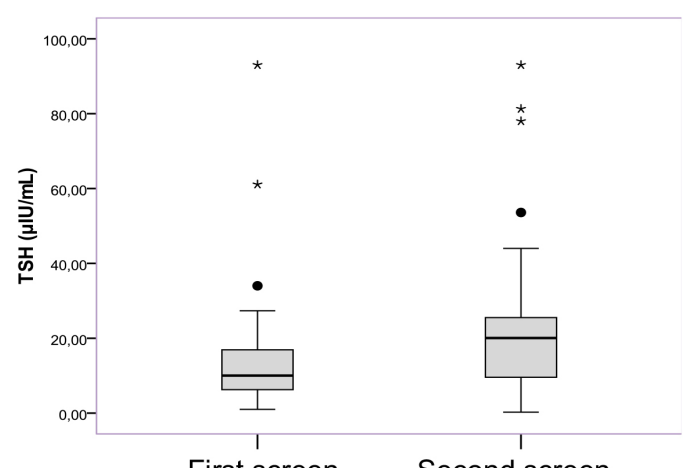

Figure 1. The first and second heel-stick TSH levels in patients with congenital hypothyroidism

TSH: Thyroid stimulating hormone

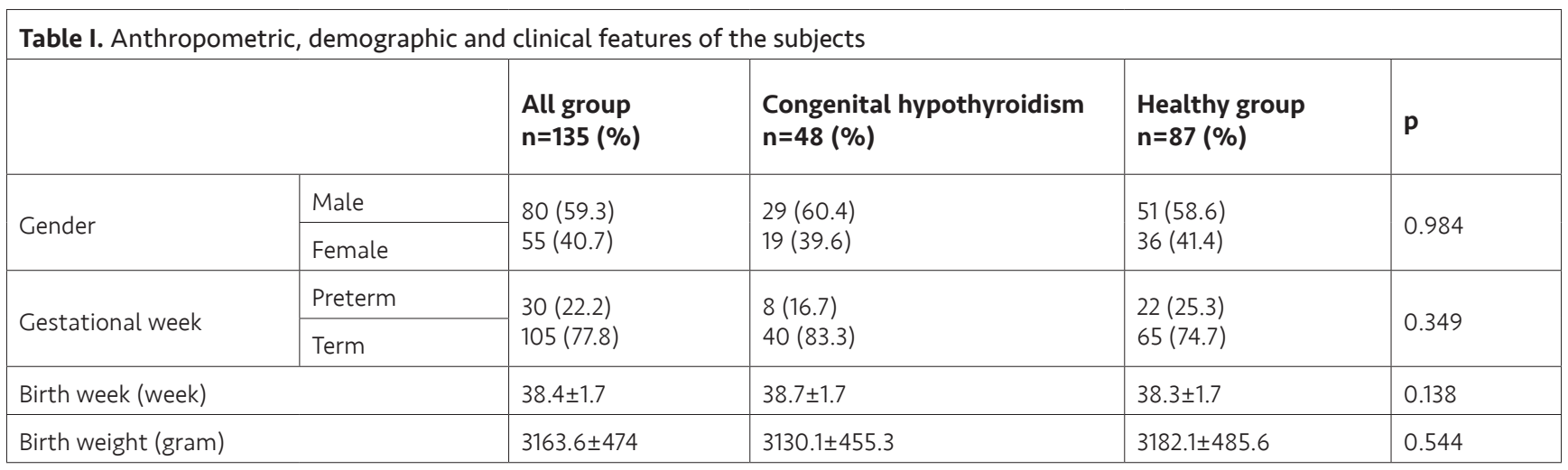

Table II. fT4 and TSH levels at admission

\begin{tabular}{|l|l|l|l|l|}
\hline & $\begin{array}{l}\text { All group } \\
\mathbf{n = 1 3 5}\end{array}$ & $\begin{array}{l}\text { Congenital hypothyroidism } \\
\mathbf{n = 4 8}\end{array}$ & $\begin{array}{l}\text { Healthy group } \\
\mathbf{n = 8 7}\end{array}$ & $\mathbf{p}$ \\
\hline TSH $(\mu \mathrm{lU} / \mathrm{mL})$ & $24.33 \pm 41$ & $62.94 \pm 49.33$ & $3.1(0.77-4.81)$ & $<0.001$ \\
\hline ST4 $(\mathrm{ng} / \mathrm{dL})$ & $0.93 \pm 0.27$ & $0.63(0.22-1.22)$ & $1.09 \pm 0.14$ & $0(0 \%)$ \\
Low $(<0.7 \mathrm{ng} / \mathrm{dL})$ & $30(22.2 \%)$ & $30(62.5 \%)$ & $87(100 \%)$ & $<0.001$ \\
Normal $(>0.7 \mathrm{ng} / \mathrm{dL})$ & $105(77.8 \%)$ & $18(37.5 \%)$ & \\
\hline \multicolumn{2}{|l}{ TSH: Thyroid stimulating hormone }
\end{tabular}


Thirty three out of 48 patients (68.8\%) had symptoms

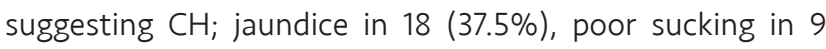
$(18.8 \%)$, and constipation in 6 cases $(12.5 \%)$. On physical examination, coarse face was detected in $3(6.3 \%)$, umbilical hernia in $2(4.2 \%)$, jaundice in $18(60 \%)$, and goiter in 2 (4.1\%) cases.

Thyroid USG was performed in $44(91.7 \%)$ out of 48 cases, and thyroid scintigraphy in $45(93.8 \%)$ cases. In 4 (9\%) cases, the thyroid gland in USC could not be visualized at normal localization. One of them was diagnosed with agenesis; and the other 3 patients were diagnosed as sublingual ectopic thyroid gland according to thyroid scintigraphy. The total volume of the thyroid gland in the other cases was calculated as $1.93 \pm 3.7 \mathrm{~mL}$, right lobe $1 \pm 1.2 \mathrm{~mL}$, left lobe $1 \pm 1.9 \mathrm{~mL}$. Hypoplasia was detected in 11 cases (25\%), normal thyroid gland in 20 cases (45.5\%), and hyperplasia in 9 cases (20.5\%) according to USC. Thyroid scintigraphy showed normal activity in $11(8.1 \%)$, increased activity in $23(17 \%)$, decreased activity in $4(3 \%)$ cases, and 4 (2.9\%) cases without gland involvement.

According to etiological classification, 16 patients (35.5\%) were classified as dysgenesis [1 agenesis (2.2\%), 3 ectopia (6.7\%), 12 hypoplasia (26.6\%)]; and 11 cases (24.5\%) as dyshormonogenesis. The remaining 18 (40\%) cases were classified as eutopic thyroid gland (Table III).

The average age at the beginning of the treatment was $17.3 \pm 9.9$ days and the dose of $L T 4$ was $12.7 \pm 2.5 \mathrm{mcg} / \mathrm{kg} /$ day.

\section{Discussion}

In this study, babies who were referred from the national screening program during a 2-year-period were retrospectively analysed, and $\mathrm{CH}$ was diagnosed in 48 (35.6\%) out of 135 cases. This rate was reported as $44 \%$ in another study conducted in our country, which is compatible with our study (5). In this study, approximately $2 / 3$ of those cases diagnosed with $\mathrm{CH}$ were male. In many studies, it has been reported that $\mathrm{CH}$ is more common in girls $(13,14)$. However, in recent studies, male dominance has been reported, similar to our study (15-17). Since dysgenesis is known to be more frequent in girls and the rate of dysgenesis is relatively low in our study, it was thought that the higher frequency of males could be related to reasons other than dysgenesis.

Bongers-Schokking et al. (18), reported that neurodevelopmental outcomes of babies with $\mathrm{CH}$ that were treated in the first two weeks were similar to a healthy group. In our study, approximately one third of the cases were admitted within the first 14 days of life and the average age of diagnosis was 17 days. In the study of Kor and Kor (15), the average age of admission was found to be $19.87 \pm 7.63$ (4-51) days and the rate of diagnosis in the first month was $88.4 \%$. Peltek Kendirci et al. (5) reported that the average age of diagnosis was $19.7 \pm 8.30$ (5-60) days and this is similar to our study. Eren et al. (19) reported the average age of diagnosis before and after the screening program to be 292 and 35 days, respectively. Although the time of diagnosis

Table III. Etiological distribution of patients with congenital hypothyroidism $(n=45)$

\begin{tabular}{|c|c|c|c|}
\hline Etiology & & Ultrasonography & Scintigraphy \\
\hline \multicolumn{4}{|c|}{ 1. Dysgenesis: $n=16$ (35.5\%) } \\
\hline \multicolumn{2}{|l|}{ Agenesis: $\mathrm{n}=1(2.2 \%)$} & No thyroid gland & No uptake \\
\hline \multicolumn{2}{|l|}{ Ectopia: n=3 (6.7\%) } & No thyroid gland & Sublingual thyroid gland \\
\hline \multirow{2}{*}{\multicolumn{2}{|c|}{$\begin{array}{l}\text { Hypoplasia: } \mathrm{n}=12(26.6 \%) \\
\text { Normal: } 1\end{array}$}} & Hypoplasia: 11 & $\begin{array}{l}\text { Decreased activity: } 3 \\
\text { Normal activity: } 1 \\
\text { Normal activity: } 4 \\
\text { No uptake: } 3\end{array}$ \\
\hline & & Decreased activity: 1 & \\
\hline \multicolumn{4}{|c|}{ 2. Dyshormonogenesis: $n=11$ (24.5\%) } \\
\hline \multirow{2}{*}{ Consanguinity } & Yes: 7 & \multicolumn{2}{|l|}{ Increased activity: 7} \\
\hline & No: 4 & Hyperplasia: 4 & Increased activity: 4 \\
\hline \multicolumn{4}{|l|}{ 3. Eutopic thyroid: 18 (40\%) } \\
\hline \multirow{2}{*}{$\begin{array}{l}\mathrm{n}=18 \\
\text { Hyperplasia: } 2 \\
\text { Normal: } 5\end{array}$} & & Normal: $10^{*}$ & Increased activity: 11 \\
\hline & & Normal activity: 7 & \\
\hline
\end{tabular}


after the screening program shifts significantly to earlier, according to many studies, the diagnosis rate is still very low in the first two weeks of life.

In this study, the venous TSH value was significantly higher in $\mathrm{CH}$ patients compared to the healthy group. In a study by Peltek Kendirci et al. (5), the mean venous TSH level was $55.2 \pm 33.5 \mu \mathrm{lU} / \mathrm{mL}(0.77-4.81)$ in patients with $\mathrm{CH}$. Similarly, in a study conducted in 223 patients with $\mathrm{CH}$, it was reported that the mean venous TSH level was 67.26 $\mu \mathrm{IU} / \mathrm{mL}$ (15). In our study, venous TSH and fT4 levels at the time of diagnosis were similar to many studies in the literature.

The most common symptom in our patients with $\mathrm{CH}$ was jaundice. Similar to our study, Özgelen et al. (20) reported that prolonged jaundice was the most common symptom in patients with $\mathrm{CH}$.

In our study, the most common cause of $\mathrm{CH}$ was eutopic thyroid gland (40\%), followed by thyroid dysgenesis (35.5\%) and dyshormonogenesis (24.5\%). In one recent study, the etiological distribution of $\mathrm{CH}$ was reported as $33.3 \%$ dysgenesis (commonly hypoplasia), $33.3 \%$ dyshormonogenesis and 16 (33.3\%) as "possible dyshormonogenesis and transient hypothyroidism" (21). In a study conducted in Egypt with 248 patients, 161 (65\%) of the cases were diagnosed with dysgenesis (107 ectopic, 28 agenesis, 26 hypoplasia), and 87 (35\%) of them with dyshormonogenesis (22). Since the etiological distribution is multifactorial; dysgenesis, dyshormonogenesis and eutopic thyroid rates differs among studies. Methodological differences are thought to be the most important reason for the etiological differences among these studies: (i) some studies used thyroid ultrasonography while others used thyroid scintigraphy for the definition of dysgenesis, and (ii) the diagnosis of dyshormonogenesis was not molecularly confirmed in most studies, hence, these factors significantly affect the etiological distribution. In addition, the frequency of transient hypothyroidism is increasing gradually. In studies published in our country, the frequency of transient hypothyroidism has been reported to be between $25-65 \%$ (23). Although the frequency of transient hypothyroidism was not defined in our study, it can be predicted that many cases with eutopic thyroid gland will be transient (24). One of the most important reasons for the increased frequency of transient hypothyroidism in recent years is the lowering of the screening TSH cut-offs. The lowering of the screening TSH cut-offs in these programs has been associated with the doubling of $\mathrm{CH}$ incidence, primarily explained by the detection of milder cases. While the whole blood TSH cut-off value in Turkey was $20 \mu \mathrm{IU} / \mathrm{mL}$ in the past, it was determined to be $10 \mu \mathrm{IU} / \mathrm{mL}$ at the start of the screening program, and was lowered to $7.5 \mu \mathrm{IU} / \mathrm{mL}$ in 2009 (4,6,2426). Accordingly, the frequency of transient $\mathrm{CH}$ increased from $27 \%$ to $56 \%$ in a period of ten years in our country (23).

\section{Study Limitations}

There are some limitations in our study: (i) the etiological distribution of $\mathrm{CH}$ was made according to the imaging findings, and molecular confirmation tests required for the definitive diagnosis of dyshormonegenesis could not be performed and (ii) Urinary iodine excretion could not be performed, so iodine excess or iodine deficiency could not be documented. The strengths of the article are; (i) it is single centre trial, (ii) the data are complete, (iii) and the imaging methods are standard and were assessed by the same physician.

\section{Conclusion}

The most common detectable causes of $\mathrm{CH}$ were shown to be dysgenesis and dyshormonogenesis. Considering that the thyroid gland is eutopic in approximately half of the cases, transient causes of $\mathrm{CH}$ might be higher than expected. Although the duration until diagnosis and initiation of treatment of $\mathrm{CH}$ were markedly reduced with the implementation of the screening program in Turkey compared to before the implementation of the screening program, the targeted and ideal time has not yet been reached for final diagnosis and the initiation of treatment ( $\leq 2$ weeks).

\section{Ethics}

Ethics Committee Approval: The study was approved by the Aydın Adnan Menderes University Faculty of Medicine, Non-Interventional Clinical Research Ethics Committee (date: 22.08.2019, approval number: 2019/125).

Informed Consent: Retrospective study.

Peer-review: Externally peer-reviewed.

\section{Authorship Contributions}

Design: T.Ü., A.A., Data Collection or Processing: D.T., A.C., Y.D.P., Analysis or Interpretation: D.T., A.A., A.C., Literature Search: Ay.A., Writing: T.Ü.

Conflict of Interest: No conflict of interest was declared by the authors.

Financial Disclosure: The authors declared that this study received no financial support. 


\section{References}

1. Wassner A). Congenital Hypothyroidism. Clin Perinatol 2018; 45:1-18.

2. Mitchell ML, Hsu HW, Sahai I. Massachusetts Pediatric Endocrine Work Group. The increased incidence of congenital hypothyroidism: fact or fancy? Clin Endocrinol (Oxf) 2011; 75:806-10.

3. Astogi MV, LaFranchi SH. Congenital hypothyroidism. Orphanet J Rare Dis 2010; 10;5:17.

4. Dilli D, Çzbaş S, Acıcan D, Yamak N, Ertek M, Dilmen U. Establishment and development of a national newborn screening programme for congenital hypothyroidism in Turkey. J Clin Res Pediatr Endocrinol 2013; 5:73-9.

5. Peltek Kendirci HN, Aycan Z, Sağsak E, Keskin M, Çetinkaya $\mathrm{S}$. The evaluation of transient hypothyroidism in patients diagnosed with congenital hypothyroidism. Turk I Med Sci 2015; 45:745-50.

6. Simsek E, Karabay M, Kocabay K. Neonatal screening for congenital hypothyroidism in West Black Sea area, Turkey. Int Clin Pract 2005; 59:336-41.

7. Sağlam H, Büyükuysal L, Köksal N, Ercan I, Tarim O. Increased incidence of congenital hypothyroidism due to iodine deficiency. Pediatr Int 2007; 49:76-9.

8. Tamam M, Adalet I, Bakir B et al. Diagnostic spectrum of congenital hypothyroidism in Turkish children. Pediatr Int 2009; 51:464-8

9. Unüvar T, Demir K, Abacı A, Ataş A, Büyükgebiz A, Böber E. Monitoring and prognostic evaluation of patients with congenital hypothyroidism treated in a pediatric endocrinology unit. Turk J Pediatr 2013; 55:384-90.

10. Léger J, Olivieri A, Donaldson $M$ et al; ESPE-PES-SLEP-JSPEAPEG-APPES-ISPAE; Congenital Hypothyroidism Consensus ConferenceGroup. European Society forPaediatric Endocrinology consensus guidelines on screening, diagnosis, and management of congenital hypothyroidism. / Clin Endocrinol Metab 2014; 99:363-84.

11. Demir K, Özen S, Konakçı E, Aydın M, Darendeliler F. A Comprehensive Online Calculator for Pediatric Endocrinologists: ÇEDD Çözüm/TPEDS Metrics. I Clin Res Pediatr Endocrinol 2017; 9:182-4.

12. Mikotajczak A, Borszewska-Kornacka MK, Bokiniec R. Sonographic Reference Ranges for the Thyroid Gland in Euthyroid Term Newborns. Am J Perinatol 2015; 32:1257-62.

13. LaFranchi SH, Murphey WH, Foley TP Jr, Larsen PR, Buist NR. Neonatal hypothyroidism detected by the Northwest Regional Screening Program. Pediatrics 1979; 63:180-91.
14. Medda E, Olivieri A, Stazi MA et al. Risk factors for congenital hypothyroidism: results of a population case-control study (1997-2003). Eur J Endocrinol 2005; 153:765-73.

15. Kor $Y$, Kor D. Current status of the congenital hypothyroidism neonatal screening program in Adana Province, Turkey. J Pediatr Endocrinol Metab 2018; 31:619-24.

16. Aminzadeh $M$. Higher prevalence of permanent congenital hypothyroidism in the Southwest of Iran mostly caused by dyshormonogenesis: a five-year follow-up study. Arch Endocrinol Metab 2018; 62:602-8.

17. Bezen D, Dilek E, Torun N, Tütüncüler F. Etiological evaluation of primary congenital hypothyroidism cases. Turk Pediatri Ars 2017; 52:85-91.

18. Bongers-Schokking IJ, Koot HM, Wiersma D, Verkerk PH, de Muinck Keizer-Schrama SM. Influence of timing and dose of thyroid hormone replacement on development in infants with congenital hypothyroidism. J Pediatr 2000; 136:292-7.

19. Eren E, Sağlam H, Zengin A, Gül Y, Papatya-Çakır ED. Evaluation of the patients with congenital hypothyroidism: effect of the national screening program. J Curr Pediatr 2011; 9:28-33.

20. Özgelen Ş, Nijat Baş V, Çetinkaya S, Aycan Z. What has national screening program changed in cases with congenital hypothyroidism? Iran / Pediatr 2014; 24:255-60.

21. Donbaloğlu Z, Savaş-Erdeve \$̧, Çetinkaya S, Aycan Z. Cases Referred from the Turkish National Screening Program: Frequency of Congenital Hypothyroidism and Etiological Distribution. J Clin Res Pediatr Endocrinol 2019; 11:240-6.

22. Bekhit $\mathrm{OE}$, Yousef RM. Permanent and transient congenital hypothyroidism in Fayoum, Egypt: a descriptive retrospective study. PLoS One 2013; 8:e68048.

23. Kara C, Günindi F, Can Yılmaz G, Aydın M. Transient Congenital Hypothyroidism in Turkey: An Analysis on Frequency and Natural Course. I Clin Res Pediatr Endocrinol 2016; 8:170-9.

24. Rabbiosi S, Vigone MC, Cortinovis F, et al. Congenital hypothyroidism with eutopic thyroid gland: analysis of clinical and biochemical features at diagnosis and after re-evaluation. I Clin Endocrinol Metab 2013; 98:1395-402.

25. Yordam N, Calikoğlu AS, Hatun S, et al. Screening for congenital hypothyroidism in Turkey. Eur J Pediatr 1995; 154:614-6.

26. Cinaz P, Yesilkaya E, Acar D, Bideci A, Camurdan O, Ayvali E. Evaluation of a neonatal congenital hypothyroidism screening programme. J Ist Faculty Med 2008; 71:78-83. 